NOTA CIENTÍFICA

\title{
ÁCIDO INDOLBUTÍRICO NO ENRAIZAMENTO DE ESTACAS SEMILENHOSAS DAS CULTIVARES DE PESSEGUEIRO DELLA NONA E ELDORADO
}

\section{INDOLBUTIRIC ACID IN ROOTING SEMIHARDWOOD CUTTINGS OF DELLA NONA AND ELDORADO PEACH CULTIVARS}

\author{
Claudinei Pedroso RIBAS ${ }^{1}$ \\ Felipe Gonçalez Dias GOMES ${ }^{1}$ \\ Rosimeri LEONOR ${ }^{1}$ \\ Luiz Antônio BIASI ${ }^{2}$ \\ Francisco Antonio MARÇALLO ${ }^{3}$
}

\begin{abstract}
RESUMO
A propagação do pessegueiro no Brasil é baseada na enxertia sobre porta-enxertos oriundos de sementes. A estaquia direta das copas poderia ser utilizada para o pessegueiro, visando a obtenção de mudas mais uniformes. O objetivo do trabalho foi avaliar o efeito do ácido indolbutírico (AIB) no enraizamento de estacas das cultivares de pessegueiro Della Nona e Eldorado. O experimento foi conduzido em casa-de-vegetação com sistema de irrigação intermitente, no período de abril a junho de 2006. As estacas foram coletadas de plantas matrizes com dois anos de idade e preparadas com $15 \mathrm{~cm}$ de comprimento e 4 folhas cortadas ao meio. O delineamento experimental utilizado foi inteiramente casualizado, com seis repetições e 16 estacas por parcela. Os tratamentos constaram das seguintes concentrações de AIB: 0, 1000, 2000 e 3000 $\mathrm{mg} \mathrm{L}^{-1}$. Após 73 dias, o experimento foi avaliado. Houve um aumento na porcentagem de enraizamento com o aumento da concentração de AIB, cujos valores máximos estimados pela equação de regressão foram de $73 \%$ e $33 \%$ de enraizamento, com as doses de $1.838 \mathrm{mg} \mathrm{L}^{-1}$ e $1.666 \mathrm{mg} \mathrm{L}^{-1}$, para as cultivares Della Nona e Eldorado, respectivamente. O AlB também estimulou o crescimento das raízes para a cultivar Della Nona, com maior comprimento $\left(9,76 \mathrm{~cm}\right.$ com $1812 \mathrm{mg} \mathrm{L}^{-1}$ de AIB) e maior número de raízes emitidas por estaca $\left(7,5 \mathrm{com} 3000 \mathrm{mg} \mathrm{L}^{-1} \mathrm{de} A \mathrm{IB}\right)$. Conclui-se que a cultivar Della Nona tem potencial para ser propagada por estaquia semilenhosa mediante uso de ácido indolbutírico.
\end{abstract}

Palavras-chave: Prunus pérsica; estaquia; raiz adventícia; auxina.

\begin{abstract}
The peach propagation in Brazil is based on grafts on seedlings rootstocks. The cutting of scion could be used to obtain better uniform plants. The objective of this paper was to evaluate the effect of the indolbutiric acid (IBA) in root cuttings of Della Nona and Eldorado peach cultivars. The experiment was carried out in a greenhouse with intermitent mist, from April until June 2006. The cuttings were collected from two-year-old stock plants prepared with $15 \mathrm{~cm}$ of length and 4 leaves cut in the middle. The experimental design was completely randomized with six reapplications and 16 cuttings per plot. The treatments were the following concentrations of IBA: 0, 1000; 2000; and $3000 \mathrm{mg} \mathrm{L}^{-1}$. The experiment was evaluated after 73 days. The percentage of root cuttings was increased with IBA concentrations, whose greatest rates were estimated by an equation of regression and were $73 \%$ and $33 \%$ of rooting with the $1838 \mathrm{mg} \mathrm{L}^{-1}$ and $1666 \mathrm{mg} \mathrm{L}^{-1}$ IBA concentrations to Della Nona and Eldorado, respectively. The IBA also promoted the root growth to cultivate 'Della Nona', with greater length $(9,76 \mathrm{~cm}$ with $1812 \mathrm{mg} \mathrm{L}^{-1}$ of IBA) and greater number of roots $\left(7,5\right.$ with $3000 \mathrm{mg} \mathrm{L}^{-1}$ of IBA). It is concluded that the Della Nona cultivars have potential to be propagated by semihardwood cuttings with IBA application.
\end{abstract}

Key-words: Prunus persica; cutting; adventitious root; auxin.

\footnotetext{
${ }^{1}$ Aluno do Curso de Agronomia da Universidade Federal do Paraná, Curitiba - PR.

${ }^{2}$ Eng. Agrônomo, Dr., Professor Associado I. Departamento de Fitotecnia e Fitossanitarismo. Setor de Ciências Agrárias. Universidade Federal do Paraná. Caixa Postal 19061. 81531-990. Curitiba-PR. E-mail: biasi@ufpr.br. Bolsista de Produtividade em Pesquisa do CNPq.

${ }^{3}$ Eng. Agrônomo, Dr., Professor Substituto. Departamento de Fitotecnia e Fitossanitarismo. Setor de Ciências Agrárias. Universidade Federal do Paraná.
} 


\section{INTRODUÇÃO}

$\mathrm{Na}$ fruticultura, a obtenção de mudas de qualidade é muito importante, porque o material propagado utilizado na formação dos pomares influencia diretamente a produção e pode ser um dos pontos diferenciais para assegurar a qualidade do produto final. A produção nacional de pêssego ultrapassa 100 mil t, de uma área colhida da ordem de 30 mil ha, estando concentrada em mais de $72 \%$ no Estado do Rio Grande do Sul, seguido de Santa Catarina (10\%) e São Paulo (9\%) (JUNQUEIRA e PEETZ, 2003). O Paraná é o quarto produtor nacional com uma área de 1.791 ha e uma produção de $17.641 \mathrm{t}$ na safra 2002/2003 (SEAB, 2007).

A cultivar Della Nona de pessegueiro apresenta vigor médio e boa capacidade produtiva. Estima-se sua necessidade de frio hibernal em cerca de $400 \mathrm{~h}$ menor ou igual a $7,2{ }^{\circ} \mathrm{C}$. Os frutos são ovalados, com sutura desenvolvida; tamanho médio e peso médio que pode ultrapassar $100 \mathrm{~g}$. A polpa é branca, com coloração vermelha ao redor do caroço, e a película apresenta de $30 \%$ a $80 \%$ de vermelho vivo sobre o fundo creme. A produtividade, na maioria dos anos, é de 30 a $40 \mathrm{~kg}$ por planta (BIASI et al., 2004).

A cultivar Eldorado apresenta frutos de tamanho grande, com peso médio geralmente em torno de $120 \mathrm{~g}$, e forma redondo-cônica, com sutura levemente desenvolvida. A película é amarela, com até $50 \%$ de vermelho, e a polpa é amarela, firme e aderente ao caroço. A necessidade de frio da cultivar é estimada em $300 \mathrm{~h}$ (BIASI et al., 2004).

A propagação do pessegueiro [Prunus persica (L.) Batsch] está baseada na enxertia de borbulhas sobre porta-enxertos provenientes de sementes. Os porta-enxertos mais utilizados pelos viveiristas na cultura do pessegueiro são 'Capdeboscq' e 'Aldrigh', na região Sul do Brasil, pelas características de vigor, resistência a pragas e doenças, aspectos qualitativos dos frutos e ausência de deformações morfológicas, entre outros. A propagação destes porta-enxertos é usualmente feita a partir de sementes, mas esse método é vantajoso para regiões próximas das indústrias de processamento, onde a obtenção dos caroços é mais prática, apresentando como inconveniente o risco de segregação genética e a mistura de cultivares, provocando a desuniformidade de plantas no pomar (FINARDI, 2003).

A estaquia pode ser utilizado tanto para porta-enxertos como para cultivares copa, pois, de acordo com FACHINELLO et al. (2005), este método apresenta uma série de vantagens, dentre as quais a maior facilidade de formação de grande número de mudas num curto espaço de tempo, fácil execução e maior uniformidade das plantas no pomar, devido à fidelidade genética.

O pessegueiro apresenta dificuldade para o enraizamento de estacas e para melhorar a eficiência dessa técnica, tem-se recorrido à aplicação de reguladores de crescimento, como o ácido indolbutírico (BIASI et al., 2000; TOFANELLI et al., 2002). OLIVEIRA et al. (2003) constataram que o uso do ácido indolbutírico (AIB) influenciou na porcentagem de enraizamento de estacas semilenhosas de pessegueiro sendo a dose satisfatória de $1500 \mathrm{mg} \mathrm{L}^{-1}$.
O objetivo deste trabalho foi avaliar o efeito de diferentes concentrações de ácido indolbutírico no enraizamento das cultivares de pessegueiro Della Nona e Eldorado.

\section{METODOLOGIA}

O experimento foi conduzido no período de abril a junho de 2006, no Departamento de Fitotecnia e Fitossanitarismo da Universidade Federal do Paraná, localizado no município de Curitiba-PR.

Utilizou-se ramos semilenhosos, coletados de plantas de dois anos de idade, das cultivares de pessegueiro Della Nona e Eldorado, de um pomar comercial localizado no município de Campo Largo - PR, em abril de 2006. As estacas foram padronizadas com comprimento de $15 \mathrm{~cm}$ e diâmetro entre 4 e $6 \mathrm{~mm}$, mantendo-se 4 folhas cortadas ao meio, no terço superior de cada estaca. Foi efetuado um corte horizontal na parte superior e um corte em bisel na parte basal das estacas.

As estacas foram imersas por $5 \mathrm{~min}$ em hipoclorito de sódio a $0,5 \%$, lavadas em água corrente e posteriormente aplicado o AIB na forma de solução hidroalcoólica a $50 \%$, mediante a imersão da base das estacas por 5 segundos (TOFANELLI et al., 2003). Os tratamentos testados consistiram das seguintes concentrações de AIB: 0 (testemunha), 1000, 2000 e $3000 \mathrm{mg} \mathrm{L}^{-1}$. No tratamento testemunha, as estacas foram imersas na solução hidroalcoólica a $50 \%$. Em seguida foi realizada a estaquia, em tubetes plásticos com capacidade de $53 \mathrm{~cm}^{3}$, contendo como substrato vermiculita de grânulos médios, com as estacas enterradas até um terço do seu comprimento. As estacas foram mantidas em casa-de-vegetação com sistema de irrigação intermitente, sendo o intervalo de rega de 15 segundos a cada $30 \mathrm{~min}$, das 8:00 as $17: 00 \mathrm{~h}$; de 15 segundos a cada hora, das $17: 00$ as 23:00 h; e de 15 segundos a cada $3 \mathrm{~h}$, das 23:00 as 8:00 h.

O delineamento experimental adotado foi inteiramente casualizado, com 6 repetições e 16 estacas por parcela. A avaliação foi realizada após 73 dias, pelas seguintes variáveis: porcentagem de enraizamento; mortalidade; porcentagem de estacas vivas não enraizadas com ou sem calo); porcentagem de estacas com calo não enraizadas; comprimento das três maiores raízes por estaca; e o número médio de raízes primárias por estaca. Os dados foram submetidos à análise de variância e as médias dos tratamentos comparadas pela análise de regressão polinomial.

\section{RESULTADOS E DISCUSSÃO}

Verificou-se que a cultivar Della Nona obteve maior porcentagem de enraizamento, quando comparada com a cultivar Eldorado (Figura 1), estimando-se pela equação de regressão os valores máximos de $73 \%$ e $33 \%$ de enraizamento, com as doses de $1838 \mathrm{mg} \mathrm{L}^{-1}$ e $1666 \mathrm{mg} \mathrm{L}^{-1}$, respectivamente. A diferença varietal na habilidade de enraizamento é conhecida entre as cultivares de pessegueiro (TOFANELLI et al., 1997; RUFATO et al., 1999; BIASI et al., 2000; OLIVEIRA et al., 2003; TOFANELLI et al., 2003). O aumento da porcentagem de enraizamento das estacas, obtido neste trabalho, confirma os resultados encontrados por CHALFUN 
et al. (1994), NACHTIGAL (1999) e TOFANELLI et al. (2002), que consideraram esse regulador indispensável para a melhoria dos índices de enraizamento de diferentes tipos de estacas formação de raízes adventícias com o uso do AIB, provavelmente, ocorreu devido à melhoria no
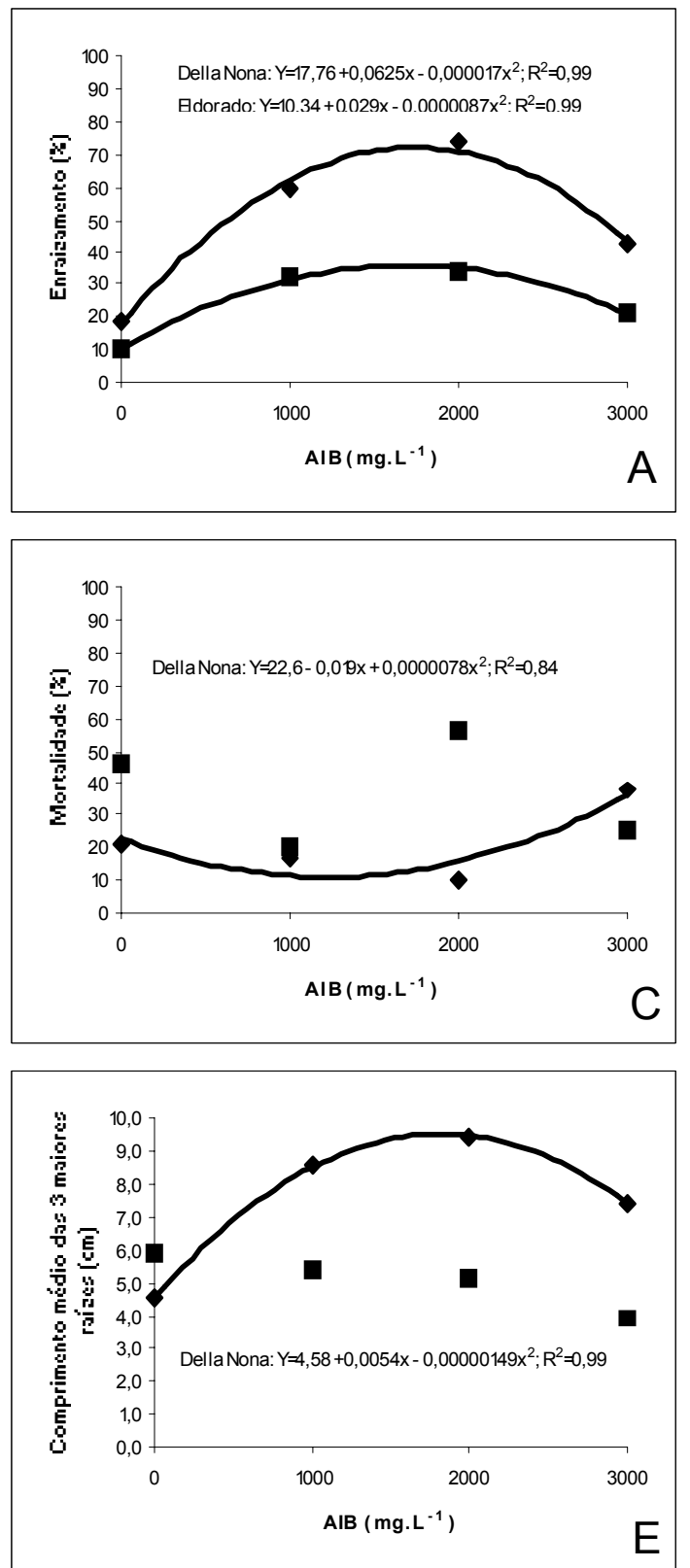
semilenhosas de pessegueiro. A maior indução da

balanço hormonal das estacas, mas também à redução do tempo necessário para iniciar o enraizamento, pois observa-se que a porcentagem de estacas vivas não enraizadas nas testemunhas de ambas as cultivares foi alto (Figura 1). Para a cultivar Eldorado, devido a baixa resposta a aplicação de AIB, apenas foi encontrada significância estatística para a porcentagem de enraizamento.
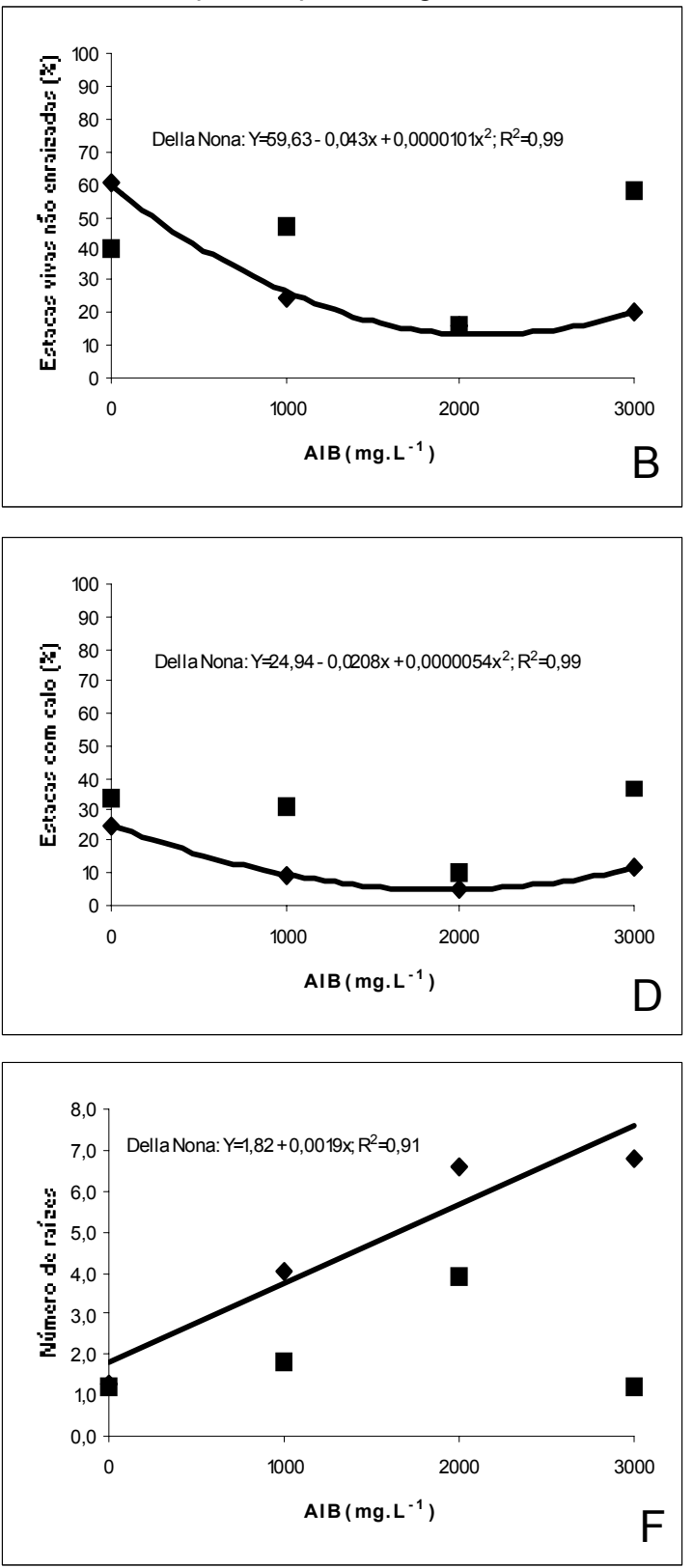

FIGURA 1 - Estaquia de pessegueiros ‘Della Nona' ( ) e 'Eldorado' ( $\quad$ ) sob diferentes concentrações de ácido indolbutírico (AIB): porcentagem de enraizamento - $A$; porcentagem de estacas vivas não enraizadas - B; mortalidade - C; porcentagem de estacas com calo - D; comprimento médio das três maiores raízes emitidas por estaca - $\mathrm{E}$; número médio de raízes emitidas por estaca - $\mathrm{F}$. Curitiba-PR. 2006.

O comportamento quadrático de incremento da porcentagem de enraizamento, em resposta ao aumento da concentração de AIB, pode estar relacionado com o fato das estacas possuírem um conteúdo endógeno de hormônios, promotores e inibidores de enraizamento, e o fornecimento exógeno de auxina promover uma alteração hormonal, favorecendo ou não o enraizamento, dependendo da quantidade absorvida (HARTMANN et al., 2002). A redução na porcentagem de estacas enraizadas além das concentrações ideais determinadas de AIB, está de acordo com os dados obtidos por ALVARENGA e CARVALHO (1983), que citam que altas concentrações de auxinas podem provocar inibição no enraizamento. Esse efeito fitotóxico também já foi observado por outros autores, com concentrações superiores a $2000 \mathrm{mg} \mathrm{L}^{-1}$ (MINDÉLLO NETO, 2005; OLIVEIRA et al., 2003; TOFANELLI et al., 2003). No presente trabalho, a mortalidade aumentou com o uso de $3000 \mathrm{mg} \mathrm{L}^{-1}$ de AIB para a cultivar Della Nona e não foi significativa para a cultivar Eldorado (Figura 1). 
A porcentagem de estacas com calo foi baixa para a cultivar Della Nona, reduzindo com o aumento das concentrações de AIB (Figura 1). Esse comportamento decorre do grande aumento de estacas enraizadas com o uso de AIB, também verificado com estacas semilenhosas das cultivares Biuti, Diamante e Pérola de Mairinque (TOFANELLI et al., 1997).

Observou-se que o AIB promoveu aumento do comprimento das raízes, sendo estimado pela equação de regressão o valor máximo na concentração de $1812 \mathrm{mg} \mathrm{L}^{-1}$ para a cultivar Della Nona (Figura 1). RUFATO et al. (1999) também observaram que o comprimento da maior raiz das estacas foi superior quando tratadas com $2000 \mathrm{mg}$ $\mathrm{L}^{-1}$ de AIB. Para esta variável, houve comportamento semelhante à porcentagem de enraizamento, com a maior concentração de AIB reduzindo o comprimento das raízes.

Para o número de raízes emitidas por estaca, a cultivar Della Nona apresentou incremento linear com o aumento da concentração de AIB, obtendo-se uma média de 7,5 raízes na concentração de $3000 \mathrm{mg} \mathrm{L}^{-1}$ de AIB (Figura 1). De acordo com NACHTIGAL (1999), não existe na literatura uma referência ao número e comprimento adequado de raízes. No entanto, esses fatores estão relacionados à capacidade de sobrevivência e de desenvolvimento da planta após o período de formação das raízes. RUFATO e KERSTEN (2000) também verificaram um efeito positivo linear, com o aumento da concentração de AIB, no número de raízes emitidas por estaca para as cultivares Esmeralda e BR2. Esse efeito foi observado para outras cultivares, como Biuti, Pérola de Mairinque (TOFANELLI et al., 1997), Capdebosq, Diamante (RUFATO et al., 1999), Ágata, Coral e Ouro (BIASI et al., 2000).

\section{CONCLUSÕES}

A cultivar Della Nona tem potencial para ser propagada por estaquia semilenhosa mediante uso de ácido indolbutírico.

\section{REFERÊNCIAS}

1. ALVARENGA, L.R.; CARVALHO, V.D. Uso de substâncias promotoras de enraizamento de estacas de frutíferas. Informe Agropecuário, v. 9, n. 101, p. 47-55, 1983.

2. BIASI, L.A.; STOLTE, R.E.; SILVA, M.F. da. Estaquia de ramos semilenhosos de pessegueiro e nectarineira. Revista Brasileira de Fruticultura, v. 22, n. 3, p. 421-425, 2000.

3. BIASI, L.A.; ZANETTE, F.; PETRI, J.L.; MARODIN, G.A.B. Cultivares de fruteiras de caroço. In: MONTEIRO, L.B.; MAY DE MIO, L.L.; SERRAT, B.M.; MOTTA, A.C.V.; CUQUEL. F.L. Fruteiras de caroço: uma visão ecológica. Curitiba: UFPR. 2004. p. 5-32.

4. CHALFUN, N.N.J.; PASQUAL, M. RAMOS, J.D.; LIMA, P.C.: CHALFUN JÚNIOR, A ; SILVA, T. das G. Efeito do anelamento e diferentes dosagens do ácido indolbutírico na propagação de estacas caulinares de pessegueiro 'Okinawa'. Revista Brasileira de Fruticultura, v. 16, n. 1, p. 119-126, 1994.

5. FACHINELLO, J.C.; HOFFMANN, A.; NACHTIGAL, J.C. Propagação de plantas frutíferas. Brasília: Embrapa Informação Tecnológica, 2005. $221 \mathrm{p}$

6. FINARDI, N.L. Descrição e métodos de propagação de porta-enxertos. In: RASEIRA, M. do C.B.; CENTELLAS-QUEZADA, A. (Eds.). Pêssego: produção. Pelotas: Embrapa Clima Temperado; Brasília: Embrapa Informação Tecnológica, 2003. p. 60-70.

7. JUNQUEIRA, A.H.; PEETZ, M.S. Aspectos relevantes dos mercados interno e externo. In: RASEIRA, M. do C.B.; CENTELLAS-QUEZADA, A. (Eds.). Pêssego: produção. Pelotas: Embrapa Clima Temperado; Brasília: Embrapa Informação Tecnológica, 2003. p. 18-30.

8. HARTMANN, H.T.; KESTER, D.E.; DAVIES JR., F.T.; GENEVE, R.L. Plant propagation: principles and practices. 7. ed. New Jersey: Prentice Hall, 2002. 880 p.

9. MINDÊLLO NETO, U.R. Enraizamento de estacas de pessegueiro em função de ácido indolbutírico e fertilizante orgânico. Revista Brasileira de Fruticultura, v. 27, n. 1, p. 94-96, 2005.

10. NACHTIGAL, J.C. Obtenção de porta-enxertos 'Okinawa' e de mudas de pessegueiro (Prunus persica (L.) Batsch) utilizando métodos de propagação vegetativa. Jaboticabal, 1999. 165 f. Tese (Doutorado em Produção Vegetal) - Universidade Estadual Paulista, Faculdade de Ciências Agrárias e Veterinárias.

11. OLIVEIRA, A.P. de; NIENOW, A.A.; CALVETE, E.O. Capacidade de enraizamento de estacas semilenhosas e lenhosas de cultivares de pessegueiro tratadas com AIB. Revista Brasileira de Fruticultura, v. 25, n. 2, p. 282-285, 2003.

12. RAMOS, J.D.; MATOS, L.E.S.; GONTIJO, T.C.A.; PIO, R.; JUNQUEIRA, K.P.;SANTOS, F.C. Enraizamento de estacas herbáceas de 'mirabolano' (Prunus cerasifera ehrn) em diferentes substratos e concentrações de ácido indolbutírico. Revista Brasileira de Fruticultura, v. 25, n. 1, p. 189-191, 2003.

13. RUFATO, L.; KERSTEN, E. Enraizamento de estacas de pessegueiro (Prunus persica (L.) Batsch), cvs. Esmeralda e $\mathrm{BR2}$, submetidas à estratificação e ao ácido indolbutírico. Revista Brasileira de Fruticultura, v. 22, n. 2, p. 191-194, 2000.

14. RUFATO, L.; ROSSI, A. de; LOMBARDI, S.R.; RIBEIRO, E.; KERSTEN, E. Efeito de diferentes concentrações de floroglucinol no enraizamento de estacas lenhosas de duas cultivares de pessegueiro (Prunus persica L. Batsch) tratadas com AIB. Revista Brasileira de Fruticultura, v. 21, n. 3, p. 297-300, 1999

15. SEAB. Secretaria de Estado de Agricultura e Abastecimento. Frutas no Paraná. Disponível em <http://www.pr.gov.br/ seab> Acesso em 18 jun 2007.

16. TOFANELLI, M.B.D; CHALFUN, N.N.J.; HOFFMANN, A.; ANTUNES, L.E.C. Enraizamento de estacas lenhosas e semilenhosas de cultivares-copa de pessegueiro em diferentes concentrações de ácido indolbutírico. Revista Brasileira de Fruticultura, v. 19, n. 2, p. 259-263, 1997.

17. TOFANELLI, M.B.D; CHALFUN, N.N.J.; HOFFMANN, A.; CHALFUN JÚNIOR, A. Efeito do ácido indolbutírico no enraizamento de estacas de ramos semilenhosos de pessegueiro. Pesquisa Agropecuária Brasileira, v. 36, n. 7, p. 939-944, 2002.

18. TOFANELLI, M.B.D.; ONO, E.O.; RODRIGUES, J.D. Método de aplicação de ácido indolbutírico no enraizamento de estacas herbáceas de pessegueiro. Revista Brasileira de Fruticultura, v. 25, n. 2, p. 363-364, 2003. 